\title{
Práticas discursivas em contextos sociais: linguagem e trabalho em uma associação de catadores de materiais recicláveis
}

\author{
Discursive practices in social contexts: \\ language and work in a collectors association of recyclable materials
}

Ernani Cesar de FREITAS*

Universidade de Passo Fundo (UPF) / Universidade Feevale (FEEVALE)

Itatiane CHIARADIA**

Universidade de Passo Fundo (UPF)

\begin{abstract}
RESUMO: Este estudo enfoca práticas discursivas de uma associação de catadores de materiais recicláveis sobre a atividade no trabalho. Tem como objetivo descrever e analisar como se constituem a cenografia e o ethos discursivo, por meio dos dizeres, na situação de enunciação, de alguns dos entrevistados integrantes do grupo pesquisado. A abordagem teórica é de base enunciativo-discursiva da linguagem, com ênfase aos conceitos de cenografia e de ethos (MAINGUENEAU, 2008a, 2008b, 2011), mediante interface com a perspectiva ergológica (SCHWARTZ, 2010a, 2010b, 2011b; TRINQUET, 2010) e a linguagem sobre o trabalho (NOURUOUDINE, 2002), destacando alguns conceitos como trabalho prescrito/real, saberes constituídos/investidos, normas/renormalizações, dramáticas do uso de si. A pesquisa mostrou que o ethos discursivo está imbricado à cenografia constituída na enunciação através da qual se instaura um estatuto particular dos enunciadores e dos enunciados, que possibilitam compreender a linguagem como fato sócio-histórico que se insere nas relações de poder que permeiam a vida social.
\end{abstract}

PALAVRAS-CHAVE: Práticas discursivas. Linguagem sobre trabalho. Ergologia. Cenografia. Ethos discursivo.

ABSTRACT: This study focuses discursive practices of a collectors association of recyclable materials about the activity work. It aims to describe and analyze how scenography and the discursive ethos are constituted, through inscriptions, in an enunciation situation, from some members of the researched group. The theoretical guiding approach is enunciative-discursive, emphasizing scenography and the ethos concepts (MAINGUENEAU, 2008a, 2008b, 2011), against the interface with the ergological perspective, (SCHWARTZ, 2010a, 2010b, 2011b; TRINQUET, 2010) and language on labor (NOURUOUDINE, 2002), outstanding some concepts like written/real work, constituted/invested knowledge, rules/renormalizations, dramatics of the self use. The research showed that the discursive ethos is imbricated to the scenography composed in the enunciation through it establishes a particular statute from the enunciators and from the statements that they make possible to understand the language like a social historical fact that introduce itself in the power relationship that permeate the social life.

KEYWORDS: Discursive practices. Language about work. Ergology. Scenography. Discursive ethos.

\footnotetext{
* Pós-doutorado em Linguística Aplicada e Estudos da Linguagem e Doutorado em Letras; professor permanente da Universidade de Passo Fundo (UPF, Passo Fundo, RS), Programa de Pós-Graduação em Letras, e da Universidade Feevale (FEEVALE, Novo Hamburgo, RS), Mestrado em Processos e Manifestações Culturais. Porto Algre- RS- Brasil. E-mail: nanicesar@terra.com.br.

** Mestrado em Letras e especialista em Psicopedagogia; docente da Universidade de Passo Fundo (UPF), Centro Integrado de Ensino. Porto Alegre - RS - Brasil. E-mail: tatichiaradia@ibest.com.br.
} 


\section{Introdução}

Este estudo se insere na temática "Linguagem e Trabalho" e, dentro desse contexto, a concepção de trabalho aqui implicada refere-se à maneira como são desenvolvidas as atividades e as relações discursivas dos sujeitos envolvidos em uma entidade de recicladores de materiais na cidade de Passo Fundo/RS, a Associação Amigos do Meio Ambiente (AAMA). Os serviços de reciclagem surgem num contexto que parece ter, ainda, pouca significação para a sociedade, mas que, devido à ênfase em relação aos cuidados com o meio ambiente, vem conquistando significativo valor socioeconômico.

Assim, com vistas a organizar pessoas em situação de vulnerabilidade social e incentivando a designada economia popular solidária ${ }^{1}$, o Projeto Transformação ${ }^{2}$, mantido pelos diversos segmentos da Igreja Católica, formou e acompanha no bairro Popular, em Passo Fundo, várias associações de reciclagem, objetivando a autonomia dos empreendimentos e de seus associados. Neste estudo, enfocaremos, em particular, uma dessas associações, constituída, atualmente, por mulheres residentes no mesmo bairro em que está localizado o empreendimento e que trabalham com a reciclagem de resíduos sólidos em geral, descartados diariamente pela sociedade. Informamos que este artigo constitui um recorte feito do texto maior, uma dissertação de mestrado concluída em novembro de 2012, na linha de pesquisa Constituição e Interpretação do Texto e do Discurso, do Programa de Pós-Graduação em Letras da Universidade de Passo Fundo, RS.

Destacamos que este estudo oportuniza uma aproximação com a comunidade em geral, em especial com as pessoas que se encontram em situação de vulnerabilidade social. Tal afirmação se justifica na medida em que um novo olhar é lançado sobre a AAMA, a maneira como as associadas gerenciam suas dificuldades organizacionais e de comunicação na rotina diária dessa entidade. Nesse sentido da interação, a linguagem é compreendida como um resultado da atividade humana diária dos sujeitos, de um modo de agir e pensar discursivo que os situa sócio-historicamente num contexto vivido e mostra a importância da interdisciplinaridade aqui representada pela abordagem teórica da ergologia, com Schwartz (2006, 2010a, 2010b, 2011b) e Trinquet (2010), da linguagem sobre o trabalho (NOUROUDINE, 2002) e da semântica global (cenografia e ethos discursivo), conforme Maingueneau (1984/2008a, 2008b, 2011) e seus estudiosos.

Diante do exposto, o problema de pesquisa a que nos propomos investigar está assim configurado: como se constroem discursivamente a cenografia e o ethos manifestados nas práticas discursivas de uma associação de material reciclável e de seus catadores? Em busca de uma resposta, partimos da hipótese que os depoimentos dos entrevistados manifestam "dizeres/discursos" específicos relativos à atividade, ao trabalho, que possibilitam construir cenografias com base nas práticas linguageiras, das quais resulta o ethos discursivo correspondente. Dessa questão de pesquisa, enunciamos o objetivo geral deste estudo: descrever e analisar como se constroem a cenografia enunciativa e o ethos discursivo de catadores de material reciclável que integram a AAMA.

\footnotetext{
1 “Entende-se por economia popular o conjunto de atividades econômicas e práticas sociais desenvolvidas pelos setores populares no sentido de garantir, com a utilização de sua própria força de trabalho e dos recursos disponíveis, a satisfação de necessidades básicas, tanto materiais como imateriais (ICAZA; TIRIBA, 2003, p. 101).

${ }^{2}$ O Projeto Transformação é desenvolvido e mantido pela Igreja Católica de Passo Fundo, em seus diversos segmentos: Cáritas Diocesana, Fundo Diocesano de Solidariedade (SEC) - Irmãs Franciscanas, Missionários da Sagrada Família, Padres Redentoristas - Escola Menino Deus, Colégio Notre Dame. Esse projeto inclui voluntários da sociedade em geral atrelados à Igreja de alguma forma, no intuito de desenvolver melhorias para os grupos que se encontram em situação de vulnerabilidade social.
} 
A metodologia utilizada durante esta investigação pautou-se pelos seguintes procedimentos: pesquisa descritivo-bibliográfica e documental, com estudo de caso e abordagem qualitativa. A coleta de dados realizou-se através da aplicação de entrevista semiestruturada e da técnica observação sistemática.

A estrutura deste artigo está disposta da seguinte forma: fundamentação teórica, que compreende conceitos do trabalho prescrito e real, normas e renormalizações, saberes constituídos e investidos, uso de si por si e de si pelo outro, práticas linguageiras na relação linguagem e trabalho, e conceitos da semântica global com enfoque aos conceitos de cenografia e de ethos discursivo. Em seguida, apresentamos a metodologia empregada e procedimentos de análise das entrevistas realizadas com duas pessoas que fazem parte da AAMA, visando à compreensão dessa entidade, sua constituição, seu funcionamento. Finalmente, expomos algumas considerações finais contemplando resultados do estudo.

\section{Moldes ergonômicos para um visão do trabalho}

No sentido de abarcar a temática deste estudo, é imprescindível valer-se de diferentes enfoques, ou seja, de diferentes áreas do saber científico para que tal tarefa obtenha algum êxito. Conforme palavras de Souza-e-Silva (2002, p. 63), "há múltiplas ciências do trabalho e não se pode pretender abordar uma realidade tão complexa a partir do ponto de vista de uma só área do saber”.

A ergonomia, neste artigo, pode ser conceituada como um conjunto de conhecimentos sobre o homem no trabalho e uma prática de ação que relaciona, de maneira muito próxima, a compreensão e transformação laboral.

Em rápido percurso histórico, de acordo com Souza-e-Silva (2004), na GrãBretanha a ergonomia objetivava a adaptação da máquina ao homem, na França ela propunha uma inversão no paradigma taylorista vigente one best way ${ }^{3}$, preocupando-se com a adaptação do trabalho ao homem, o que remete ao âmbito da ergonomia situada ou da atividade, de forma que se compreenda atividade como realização, por oposição à tarefa, como prescrição de objetivos e de procedimentos. Depreendemos, então, que com os ergonomistas foi constatada uma distância entre o que está prescrito e o modo como ele é realizado, com base em estudos e na observação situada do trabalho. Essa distância caracteriza-se por um “debate de valores” entre trabalho prescrito e trabalho real.

Há, portanto, um intervalo que não se elimina entre o trabalho que está prescrito e o trabalho real, conforme nos ensina a ergonomia (CLOT, 2007; SCHWARTZ, 2002, 2006). É nesse intervalo, caracterizado pela defasagem e insuficiência dos procedimentos, regras e normas, que, por si só, não garantem a realização do trabalho, que o trabalhador irá construir, de forma parcialmente singular, o jeito de fazer sua tarefa.

Freitas (2011, p. 108) salienta que o trabalho prescrito “[...] corresponde aos documentos que instruem, ensinam, aconselham etc. o trabalho a ser realizado. Instituições ou empresas os produzem anteriormente à realização efetiva do trabalho para representar o que deve (ou não) e como deve ser feito”. Nesse sentido, a prescrição tem o objetivo de estabelecer normas que devem ser seguidas por um determinado grupo de profissionais e que, mesmo não sendo adotadas, norteiam a realização da atividade. Porém, na atividade real de trabalho, atualiza-se uma interpretação individual dessas normas, de acordo com a história de vida, da subjetividade de cada trabalhador e do coletivo ao qual ele pertence.

\footnotetext{
${ }^{3}$ Conceito taylorista traduzido como “[...] uma única maneira certa de executar uma tarefa” (RIBEIRO, 2007, p. 72).
} 
Os estudos acerca do trabalho receberam, pois, aportes preciosos dos conceitos ergonômicos de trabalho prescrito e trabalho real, possibilitando um novo olhar sobre a atividade humana. A partir desses conceitos, considerando que é impossível imaginar a atividade como um mero ato de cumprimento do prescrito, Schwartz (2002, 2010b) propõe uma ampliação dessa compreensão para um espaço de debate de normas antecedentes e renormalizações, concebendo, assim, a ergologia.

\section{A perspectiva ergológica e a singularidade da atividade na relação linguagem e trabalho}

De acordo com Nouroudine (2002), a relação trabalho/linguagem configura-se em três modalidades, a saber: linguagem sobre o trabalho, a linguagem no trabalho e a linguagem como trabalho, constituindo, portanto, as práticas linguageiras.

Neste estudo, particularmente, nos atemos à modalidade linguagem sobre o trabalho. Em relação à linguagem sobre o trabalho, Nouroudine (2002, p. 26) destaca que esta é, muitas vezes, motivada por exigências da equipe ou da instituição para comentá-lo ou avaliá-lo, para lembrar, para se justificar. Mesmo assim, porém, “[...] é pertinente o questionamento acerca de 'quem fala? ', 'de onde ele/ela fala? ', 'quando ele/ela fala? ' para que se compreenda onde se situa o campo de validade de pertinência da 'linguagem sobre o trabalho"”.

Nouroudine (2002) entende ser a linguagem um dispositivo revelador da complexidade do trabalho, o que é enfatizado por Di Fanti (2012), pois “a linguagem como trabalho possui uma complexidade idêntica à de toda a atividade de trabalho" (NOUROUDINE, 2002, p, 18). As observações realizadas pelos analistas do trabalho revelam que "de modo oposto ao que o taylorismo tentava demonstrar, sem, todavia, realmente conseguir, o trabalho não é simples” (NOUROUDINE, 2002, p. 19), é complexo, no sentido de ser composto de várias dimensões intrínsecas: econômica, social, cultural, jurídica etc.

A complexidade do trabalho também é a da linguagem no que o trabalho comporta de linguagem. Sobre essa intricada relação, Nouroudine (2002) destaca que Catherine Teiger parte da hipótese de que, nas situações de trabalho, a linguagem como atividade integra aspectos estratégicos definíveis como "fala para si e fala ao outro, para o outro, centrada essencialmente aqui nos desafios da realização do trabalho e da existência da identidade pessoal dentro e pelo grupo, sobretudo através do tempo (...)” (TEIGER, 1995, p. 67 apud NOUROUDINE, 2002, p. 19).

Uma das perspectivas teóricas relacionadas ao estudo sobre o trabalho que traz contribuições relevantes à dimensão da singularidade (no trabalho) é a Ergologia. “A ergologia é um método de investigação pluridisciplinar em função de a atividade humana ser muito complexa para se compreender e analisar a partir de uma única disciplina, qualquer que seja ela. Todas são necessárias, embora nenhuma seja suficiente" (TRINQUET, 2010, p. 94). O estudo das noções ergológicas, neste artigo, é de fundamental importância para desenvolvermos as questões relacionadas às atividades de trabalho da Associação Amigos do Meio Ambiente, que a seguir são tratadas.

O trabalho, conforme entendimento do filósofo Ives Schwartz (2011b, p. 20), considerado o criador da abordagem ergológica, "é uma realidade enigmática”, porque “escapa a toda definição simples e unívoca”. Essa compreensão, conforme Di Fanti (2012), encontra-se no cerne da ergologia, que teve três grandes influências em sua formação: a experiência de pesquisa-intervenção do médico e psicológo italiano Ivar Oddone, as reflexões da ergonomia da atividade, em especial a de Alain Wisner, e a filosofia de 
George Canguilhem (SCHWARTZ, 2006, p. 459-460). De acordo com Di Fanti (2012), Oddone desenvolveu com seu grupo o conceito de "comunidade científica ampliada", visando aproximar, em um contexto histórico singular, os operários da Fiat italiana, os integrantes dos sindicatos e o pessoal da universidade; surgiu a inspiração de propor a aproximação da academia ao mundo do trabalho. Da ergonomia da atividade, que constatou existir no trabalho uma distância entre o prescrito e o real, uma lacuna segundo Wisner (1994), contrapondo-se à visão positivista do regime taylorista, que considerava o trabalhador um mero executor das prescrições, resgatou o conceito de atividade humana de trabalho. Da filosofia da vida de George Canguilhem, baseou-se para ampliar o conceito de atividade, considerando-a como "atividade industriosa [que] envolve sempre um debate de normas", "o que remete à relação entre o social e o singular, à possibilidade de escolhas" (DI FANTI, 2012, p. 314).

A ergologia propõe-se a se aproximar desse mundo complexo que é o homem e sua atividade de trabalho, complexidade essa desconsiderada pelo taylorismo, pela chamada “organização científica do trabalho” e mesmo pelo toyotismo. Duraffourg e Durrive (2010, p. 81) enfatizam que "a norma [...] está do lado do prescrito, a renormalização do lado da atividade. Ter um posicionamento ergológico é escolher estar nesta vertente para praticar o seu ofício”. A norma dá-se como regra pela hierarquia, e o trabalhador para executar a atividade recorrerá, constantemente, à renormalização.

A ergologia estuda, portanto, toda a atividade humana, destacando-se a atividade no trabalho. O objetivo dessa disciplina, como explicam Duraffourg e Durrive (2010, p. 81), é conhecer e analisar as condições em que a "atividade laboriosa" se realiza, o que permite organizá-la, torná-la mais eficaz e rentável; e seu método consiste em "colocar em diálogo a pluridisciplinaridade dialética dos saberes eruditos e dos saberes de experiência organizados num dispositivo dinâmico de três polos (DD3P) ${ }^{4}$ : o polo dos conceitos, o da experiência e um terceiro, ético e epistêmico, que faça a ligação entre os dois. O dispositivo em três polos é uma consequência direta da ideia de renormalização da atividade. "A atividade é tomada no sentido de atividade interior. É o que se passa na mente e no corpo da pessoa no trabalho, em diálogo com ela mesma, com o seu meio e com os 'outros'”. (TRINQUET, 2010, p. 96, grifo do autor).

Schwartz (2010a) reitera existir uma distância entre trabalho prescrito e o real, definindo-os da seguinte forma: o primeiro é tido como uma entidade pensada teoricamente e com antecedência, raramente por aquele que o realiza; "O trabalho real é o campo por excelência do sentimento de vida contrariada” (CANGUILHEM, 1990); o segundo é aquele realizado por uma determinada pessoa em dado lugar. Isso revela uma constante reorganização do trabalho. De acordo com o autor, essa distância é sempre ressingularizada e cria algo parcialmente único. Essa entidade que racionaliza sobre o fazer da atividade, o corpo-si, é considerada uma presença do sujeito nem sempre consciente de como gerir tal distância. Segundo Schwartz (2010a, p. 44), o corpo-si "atravessa tanto o intelectual, o cultural, quanto o fisiológico, o muscular, o sistema nervoso", o que significa que os sujeitos fazem escolhas, as quais pressupõem um debate interno que permite acessálas.

De acordo com Freitas (2011, p. 109, grifo do autor), “o trabalho é uso de si por si, uma vez que no processo de atividade o sujeito mobiliza seu saber-fazer, seus valores, seus

\footnotetext{
${ }^{4}$ DD3P: Dispositivo dinâmico de três polos “é o lugar do encontro, o lugar do trabalho em comum em que se ativa uma espécie de espiral permanente de retrabalho dos saberes, que produz retrabalho junto às disciplinas, umas em relação às outras, portanto que transforma eventualmente um certo número de hipóteses, de conceitos entre as disciplinas. [...]. Cada uma é um reservatório de competências, mas deve se retrabalhar em si mesma [...] nessa espécie de turbilhão permanente” (SCHWARTZ, 2010c, p. 267).
} 
afetos e, enfim, sua singularidade”. É isso, portanto, que faz que cada experiência seja única e com total impossibilidade de uniformizá-las. Além disso, o trabalho é uso de si pelos outros. Assim, embora realize suas atividades a partir de ordens e procedimentos dos quais não é autor, o sujeito as ressingulariza, pois faz escolhas e essas implicam debates de normas ou dramáticas do uso de si' que perpassam todos os aspectos da vida das pessoas (SCHWARTZ, 2011b).

Desse modo, o sujeito da ergologia sempre reconfigura o trabalho, as normas de acordo com as necessidades impressas no momento. Souza-e-Silva (2002, p. 72) afirma que "o retrabalho permanente das normas supõe também um retrabalho dos discursos", o que remete ao entrelaçamento da ergologia e da linguagem, e, nesse sentido, o sujeito da ação necessita ser considerado em relação ao seu discurso e aos seus saberes. Trata-se, por conseguinte, conforme Clot (2011, p. 72) ao resgatar palavras de Espinosa (1965), do "desenvolvimento do poder de agir sobre o mundo e sobre si mesmo, coletiva e individualmente, para escapar das 'paixões tristes' do resentimento”. Ainda, nas palavras de Canguilhem (1900, p. 130): "só podemos aceitar a vida sob a condição de sermos grandes, de nos sentirmos no nascedouro dos fenômenos, ao menos de um certo número deles. Se não tivermos poder para desabrochar, se não tivermos um certo domínio das coisas, a vida é indefensável”.

Segundo Faïta (2002, p. 50), “a competência e os saberes dos sujeitos nos parecem incorporados às maneiras de dizer e às maneiras de agir orientadas a um objetivo comum”. Esse autor evidencia que o saber é construído pelo sujeito, cujo ethos vai se revelar a partir de uma cenografia, qualquer que seja sua história de vida. Neste estudo, analisaremos a cenografia e o ethos discursivo que se fazem presentes nas "falas/discursos" dos entrevistados integrantes da Associação Amigos do Meio Ambiente.

$\mathrm{Na}$ próxima seção, desenvolvemos o percurso da linguagem como evolução humana, abordando conceitos da semântica global, com ênfase especial aos conceitos de cenografia e de ethos, por serem basilares da análise enunciativo-discursiva empreendida neste estudo.

\section{Semântica global: na ordem do enunciado e na ordem da enunciação}

\subsection{Cena de enunciação em análise do discurso}

A semântica global permite uma visão ampla das dimensões discursivas a partir de seu entrelaçamento e também valoriza o discurso, em vez de apenas enunciados soltos (MAINGUENEAU, 1984/2008a). Pelos enunciados, verificamos, na constituição do discurso, a presença de vários planos integrados, tanto na ordem da enunciação quanto na do enunciado: a intertextualidade, o vocabulário, os temas tratados, o modo de coesão, bem como os planos que são utilizados neste estudo: o estatuto do enunciador e do destinatário, a dêixis enunciativa e o modo de enunciação, visto que através desses planos constitutivos, da semântica global, é que estabelecemos estreita relação com a situação de enunciação da qual se depreendem a cenografia e o ethos discursivo que se verificam nos depoimentos dos sujeitos entrevistados nesta pesquisa.

Assim, Maingueneau (1997), aprofundando os estudos dos planos constituintes da semântica global, revitaliza noções conceituais sobre o estatuto do enunciador e do destinatário, a dêixis enunciativa e o modo de enunciação para introduzir os conceitos de cenografia e ethos de forma mais específica. E é a partir desse panorama teórico-conceitual que desenvolveremos os aportes teórico-metodológicos que dão suporte a este estudo. 
Conforme Maingueneau (2008a, p. 87, grifo do autor), “cada discurso define o estatuto que o enunciador deve se atribuir e o que deve atribuir a seu destinatário para legitimar seu dizer”. Em termos de discurso, tanto o enunciador quanto o destinatário dispõem de um lugar e, nesse espaço, o enunciador projeta uma imagem de si (um ethos) no discurso a partir da qual se legitima. As categorias de enunciador e de destinatário correspondem às pessoas que fazem parte da situação de comunicação; não se trata, pois, dos sujeitos empíricos. Desse modo, tanto o enunciador quanto o destinatário estão relacionados à cena da enunciação, os quais demarcam seu posicionamento e validam o dizer.

Associado ao estatuto do enunciador e do destinatário, o discurso comporta uma série de marcas as quais o situam no espaço e no tempo: a dêixis enunciativa. É essa propriedade que "define de fato uma instância de enunciação legítima, delimita a cena e a cronologia que o discurso constrói para autorizar sua própria enunciação". (MAINGUENEAU, 2008a, p. 89, grifo do autor). Ressaltamos, contudo, que a dêixis não implica marcas empíricas, por exemplo, datas; ela estabelece uma cena e uma cronologia de acordo com as coerções de determinado posicionamento discursivo. São essas coerções, esse conjunto de regras, que definem o espaço e o tempo no interior de um discurso; devese considerar a situação que constrói o discurso e a partir desta o que se pretende e se pode enunciar.

Além dos planos por ora apresentados, o discurso é determinado, também, por uma maneira de dizer específica de acordo com cada posicionamento. Falamos do modo de enunciação, que comporta as mesmas restrições semânticas que orientam o conteúdo do discurso, ou seja, o conteúdo do discurso toma corpo de acordo com o modo de enunciação; nesse sentido, o enunciador de um discurso não é apenas uma coordenada institucional; ele constrói-se discursivamente pelo tom, caráter e corporalidade específicos (MAINGUENEAU, 2008a).

Maingueneau (2008b) destaca que a cena de enunciação é ao mesmo tempo a fundação ou a atualização de um já dito e a sua legitimação, a validação daquilo que funda ou atualiza, pois todo discurso tem intenção de convencer, fazendo reconhecer a cena de enunciação que ele impõe e por intermédio da qual se legitima; em vista disso, compreendemos que o dito e o dizer se sustentam reciprocamente.

A respeito da enunciação, Maingueneau (2008b) menciona três importantes cenas: a englobante, a genérica e a cenografia. "Juntas, elas compõem um 'quadro' dinâmico que torna possível a enunciação de um determinado discurso”. (FREITAS, 2010, p. 179). A cena englobante refere-se ao tipo de discurso, que pode ser político, religioso, administrativo etc.; os locutores, por sua vez, "só interagem nas cenas englobantes através de gêneros de discurso específicos, de sistema de normas: pode-se então falar de 'cena genérica'” (MAINGUENEAU, 2010, p. 206, grifo do autor). A cenografia é construída pelo próprio texto e não diz respeito a um espaço físico, como se o enunciador pertencesse a um ambiente 'emoldurado', mas sim a um espaço que é validado por meio da própria enunciação. "[...] a cenografia não é simplesmente um quadro, um cenário, como se o discurso aparecesse inesperadamente no interior de um espaço já construído e independente dele: é a enunciação que, ao se desenvolver, esforça-se para constituir o seu próprio dispositivo de fala”. (MAINGUENEAU, 2011, p. 87).

Além da cenografia englobante, genérica e cenografia, a cena enunciativa pode remeter a representações já instauradas na memória coletiva: são as cenas validadas. Maingueneau (2011, p. 92) faz a seguinte consideração quanto à cena validada: "se falamos de 'cena validada' e não de 'cenografia validada' é porque a 'cena validada' não se caracteriza propriamente como discurso, mas como um estereótipo automatizado, 
descontextualizado, disponível para reinvestimentos em outros textos”. Nesse sentido, temos como pressuposto que não há cenografia com ausência da língua, pois esta a investe de sentidos. Logo, seria contraditório afirmar que a língua é um instrumento de comunicação neutro; ela é investida de sentidos que serão evidenciados conforme seu uso, que poderá ser social, um dialeto etc.

Na próxima seção, apresentamos conceitos referentes ao ethos discursivo e à imagem de si com a finalidade de analisar como ele se constitui na cenografia da Associação Amigos do Meio Ambiente, nosso objeto de estudo.

\subsection{Ethos discursivo e a imagem de si: o entrelaçamento com a cenografia}

A noção de ethos teve início com os estudos de Aristóteles sobre a retórica e, para o filósofo, o conceito de ethos está ligado tão somente à persuasão, a qual configura o elemento constituinte da arte. Para Aristóteles, o ethos visava a causar boa impressão mediante o discurso e, com isso, ganhar a confiança do auditório (MAINGUENEAU, 2008c). A retórica antiga é caracterizada pelos argumentos (logos), paixões (pathos) e costumes (ethos). O ethos aristotélico restringe-se apenas à oralidade; no caso do ethos discursivo - compreensão adotada a este estudo -, ele é válido tanto para o discurso oral quanto para o escrito.

A concepção discursiva de ethos, utilizada neste artigo, advém da semântica global e é aplicada a discursos que não necessariamente apresentem sequências argumentativas. Ainda que em Gênese dos discursos Maingueneau (1984/2008a) não empregue diretamente a terminação 'ethos', o modo de enunciação - um dos planos constitutivos do discurso - dispõe de propriedades intrínsecas à construção do ethos discursivo. É o posicionamento do enunciador que definirá seu modo de enunciação, ou melhor, seu ethos. Nesse particular, não podemos reduzir o ethos, na análise do discurso, a um mecanismo de persuasão; ele é intrínseco à cena de enunciação.

Desse modo, a noção de ethos, para Maingueneau (2008b), vai além de objetivos persuasivos; todo discurso apresenta um ethos, o qual consiste em um processo de enlaçamento com a cena enunciativa. Isso não significa que todo discurso já dispõe de uma imagem pronta como se fosse algo que pudesse ser identificado na sua imediaticidade; ao mesmo tempo que o enunciador constrói seu ethos para validar seu discurso, é o próprio discurso que também valida e dá corpo ao enunciador. É como um processo em espiral.

Maingueneau (2011) faz um desdobramento do conceito de ethos; este resulta da interação de ethos pré-discursivo ou ethos prévio; ethos discursivo (ethos mostrado e ethos dito); ethos efetivo. O ethos pré-discursivo ou prévio corresponde à imagem que o coenunciador faz do enunciador antes mesmo que este fale; isso é possível visto que o ethos está intimamente relacionado à cenografia e, consequentemente, ao gênero discursivo. A diferença entre o ethos dito e o ethos mostrado - ethos discursivo - está na forma como o enunciador constrói sua própria enunciação. No caso do ethos dito, "trata-se das diferentes formas que o fiador utiliza para evocar, indiretamente, o ethos do discurso que ele materializa” (SILVA, 2006, p. 183). O ethos mostrado diz respeito a todas as marcas - semântica global - que particularizam o modo de dizer e de ser do enunciador. "A distinção entre ethos dito e mostrado se inscreve nos extremos de uma linha contínua, uma vez que é impossível definir uma fronteira nítida entre o 'dito’ sugerido e o puramente ‘mostrado’ pela enunciação” (MAINGUENEAU, 2008c, p. 18, grifo do autor). Quanto ao ethos efetivo, este é resultado da interação das diversas instâncias (entre ethos prédiscursivo e discursivo, entre ethos dito e mostrado). 
Consideramos, então, que ethos mais cenografia constitui um processo de enlaçamento. "São os conteúdos desenvolvidos pelo discurso que permitem especificar e validar o ethos, bem como sua cenografia, por meio dos quais esses conteúdos surgem" (MAINGUENEAU, 2008c, p. 71).

Quando mencionamos o processo de enlaçamento e retomando a noção de cenografia com a metáfora do cenário, fica claro que o ethos discursivo é revelado à medida que todos os planos são avaliados em determinado discurso. Estatuto do enunciador, coenunciador, dêixis discursiva e a própria escolha lexical são propriedades intrínsecas à construção da 'imagem de si'. O coenunciador, por exemplo, não é apenas um mero receptor de ideias, mas é “alguém que tem acesso ao 'dito' através de uma 'maneira de dizer' que está enraizada em uma 'maneira de ser', o imaginário de um vivido" (MAINGUENEAU, 1997, p. 49). Conforme Freitas (2010, p. 180), o "ethos liga-se ao orador, por meio, principalmente, das escolhas linguísticas feitas por ele, as quais revelam pistas acerca da linguagem do próprio orador, continuamente construída no âmbito discursivo".

Dessa forma, por meio do 'tom' da enunciação, existe a possibilidade de revelar a personalidade do enunciador, os traços do seu caráter, não importando se estes são sinceros ou não. Na expressão de Souza-e-Silva e Rocha (2009, p. 14, grifo dos autores), “o sentido propiciado pelo discurso impõe-se tanto pelo ethos como pelas 'ideias' que transmite; essas ideias se apresentam por uma maneira de dizer que remete a uma maneira de ser". Essa maneira de dizer compreende o tom que permite ao enunciador (fiador) se revelar ao coenunciador.

Esse caráter e essa corporalidade do fiador são construídos na sociedade em que ele vive, por pressão da qual essas características podem ser valorizadas ou desvalorizadas, e, assim, a enunciação pode confirmá-las ou modificá-las. O fiador, por meio do seu tom, atesta o que é dito, tanto no escrito como no oral. Maingueneau (2011, p. 99, grifo do autor) defende que "a qualidade do ethos remete, com efeito, à imagem desse "fiador" que, por meio de sua fala, confere a si próprio uma identidade compatível com o mundo que ele deverá construir em seu enunciado”.

A introdução do conceito de fiador compõe a reformulação teórica de Maingueneau (2008c), que assume ter deformado o ethos por se distanciar da prática oratória e privilegiar o texto escrito. O fiador compreende uma representação construída pelo leitor a partir de pistas textuais, recebe caráter ou traços psicológicos e corporalidade constituição corporal, vestimenta e mobilidade espacial - que se sustentam em um conjunto partilhado ou cristalizado de representações sociais, passíveis de avaliação coletiva.

Maingueneau (1997, p. 48, grifo nosso) acredita que "por estar diretamente associado à questão da eficácia de um discurso o ethos tem um status particular, ele tem a capacidade de suscitar a crença na linguagem, mediada pela enunciação”. Desse modo, o coenunciador não adere a um discurso apenas porque são apresentadas ideias ligadas aos seus possíveis interesses, mas porque esse enunciador é alguém que tem acesso ao dito, por meio de uma maneira de dizer, a qual tem suas raízes numa maneira de ser, o imaginário de um vivido.

Na sequência, os procedimentos metodológicos utilizados neste estudo são descritos e através dos quais analisamos o corpus de pesquisa. 


\section{Procedimentos metodológicos e análise}

\subsection{Caracterização da unidade do estudo}

Este estudo teve como propósito investigar o discurso sobre e no trabalho e os enunciados dos trabalhadores da Associação Amigos do Meio Ambiente, fundada em Passo Fundo no dia 4 de dezembro de 2008. Atualmente, essa Associação está constituída formalmente, possuindo regimento interno com normas construídas pelos associados, e tem como membros catadores de materiais recicláveis, integrantes esses cujo número tem variado entre 8 a 15 pessoas, contando com um representante da Igreja Católica, indicado pelo Projeto Transformação, para monitorar e coordenar o grupo.

Salientamos, entretanto, que a estrutura física e o maquinário utilizado, tais como prensas, elevador, Equipamentos de Produção Individual (EPIs) etc., pertencem à Igreja Católica. A AAMA recebe, ainda, auxílio da Prefeitura Municipal de Passo Fundo, que disponibiliza ao grupo um caminhão para recolher o material reciclável doado pela comunidade em geral.

Hoje, a AAMA está representada, juridicamente, por uma presidente, uma vicepresidente, uma tesoureira, uma secretária e uma conselheira, sendo esta a única que faz parte da Associação desde a sua fundação. Na sua maioria, as associadas não sabem ler nem escrever, e todas são católicas. Ressaltamos, também, que apenas uma das integrantes realiza a coleta de materiais nas ruas da cidade com um 'carrinho' e que os proventos percebidos pela Associação são de fundamental importância para o provento das famílias, quando não a única forma de sobrevivência.

\subsection{Percurso metodológico}

Em relação a seus objetivos, o estudo caracteriza-se como exploratório, pois, conforme Prodanov e Freitas (2009, p. 62), tem como finalidade proporcionar mais informações sobre o assunto que vamos investigar, possibilitando sua definição e seu delineamento, isto é, facilitar a delimitação do tema da pesquisa; orientar a fixação dos objetivos e a formulação das hipóteses ou descobrir um novo tipo de enfoque para o assunto”. Em relação aos procedimentos técnicos, este trabalho foi realizado por meio de pesquisa bibliográfica, documental, e de um estudo de caso com abordagem qualitativa para fins de análise.

A pesquisa documental foi necessária visto ter sido importante consultar o estatuto social e o regimento interno da entidade, para que pudéssemos melhor compreender o contexto sócio-histórico em que se situa a entidade objeto de investigação. O estudo de caso visa a explicar as práticas de linguagem discursivas, em situação de trabalho, entre os associados da AAMA, a partir da cenografia e do ethos discursivo decorrentes dos relatos feitos pelos entrevistados, sujeitos de pesquisa, e envolve análise e interpretação dos dados obtidos, apresentados num encadeamento lógico que proporcionará ao leitor melhor compreensão.

Nesta pesquisa, utilizamos amostra não probabilística que "pode ser composta de forma acidental ou intencional”. Optamos pela amostra intencional ou de seleção racional, que "constitui um tipo de amostragem não probabilística e consiste em selecionar um subgrupo da população que, com base nas informações disponíveis, possa ser considerado representativo de toda a população” (PRODANOV; FREITAS, 2009, p. 109). Foram entrevistados na Associação, para fins da pesquisa como um todo, 4 pessoas de um total de 13 (a maioria analfabetas), sendo três associadas e um agente social representante da Igreja 
Católica, o qual acompanha o empreendimento, fornecendo aos seus membros diversas informações sobre o mundo dos negócios e, sobretudo, sobre a importância das interações e relações sociais. Para fins deste artigo, elegemos a entrevista com o coordenador (ensino superior em andamento) e uma das associadas (ensino médio completo) que exerce liderança no grupo de mulheres catadoras de materiais recicláveis, e também por ser uma das associadas mais antigas na entidade. Esse recorte feito deve-se ao fato de não estendermos demasiadamente este texto; assim, escolhemos os dois entrevistados cujos depoimentos nos pareceram mais instigantes para serem apresentados e analisados neste estudo.

Complementarmente à técnica de entrevista semiestrutrada, utilizamos a observação sistemática que pressupõe planejamento para a organização e o registro dos dados coletados. Conforme Prodanov e Freitas (2009, p. 115), nessa instância, “é preciso estabelecer, antecipadamente, as categorias necessárias à análise da situação”, que, neste estudo, foram estabelecidas a partir do referencial teórico que fundamenta a pesquisa.

Com o intuito de responder à questão problematizadora deste estudo: "como se constroem discursivamente a cenografia e o ethos manifestados nas práticas de linguagem de uma associação de material reciclável e de seus catadores?”, apresentamos, na sequência, de forma mais estreita, o roteiro metodológico que norteou a interpretação e a análise dos dados coletados.

Esclarecemos que não foi estabelecida hierarquia para a análise, conforme a ordenação apresentada nos itens abaixo. Esse roteiro metodológico norteador fez-se necessário, visto que existem momentos na análise em que ora prevalecem alguns enfoques, ora outros, com ênfase aos conteúdos obtidos no corpus de pesquisa entrevistas realizadas com o coordenador da entidade e mais uma associada -; tomamos como referência pistas/marcas linguístico-discursivas presentes no material que selecionamos nos depoimentos coletados.

Para fins de melhor compreensão da análise, registramos o seguinte percurso metodológico com destaque para a interface entre:

a) Ergologia da atividade: verificamos conceitos sobre normas antecedentes (o prescrito) e renormalizações (o real), bem como o que se refere à operacionalização dos saberes constituídos e investidos; as relações entre os valores, o saber e o agir em competência; a 'dramática do uso de si', representada na linguagem sobre o trabalho, ou seja, o uso de si por si e o uso de si pelos outros; as relações entre os valores, o saber e o agir em competência;

b) Semântica global - cenografia e ethos: o estatuto do enunciador e do destinatário: marcas de pessoa no discurso - eu, tu, nós; a dêixis enunciativa temporal e espacial; o modo de enunciação (maneiras de dizer) através de enunciações/enunciados, cujos discursos são marcados linguisticamente por especificidades do dizer, ou seja, da linguagem sobre o trabalho.

\subsection{Resultados e análise}

Na sequência, destacamos alguns segmentos discursivos extraídos da entrevista realizada com o coordenador da AAMA, dando ênfase ao modo como esse sujeito percebe a entidade, tendo em vista seus próprios enunciados. Vejamos: 


\section{Quadro 1 - Segmento discursivo 1}

Questão três: Você prescreve tarefas à Associação? Se sim, de que forma: oral ou escrita? Se não, quem prescreve?

Resposta: Elas [as associadas] gostariam que eu mandasse, elas esperam um chefe, alguém de "fora" que diga o que fazer e como fazer... Não querem pensar, não querem obedecer às outras: a presidente, por exemplo. Elas dizem, quando uma delas manda fazer alguma coisa: Quando você assinar minha carteira eu faço. Não chegam a brigar, mas ficam se "espetando", se "cutucando" e eu que tenho que cuidar disso para que não briguem, elas se queixam pra mim e se queixam que eu não faço as coisas.

Questão seis: Você tem intenção de intervir em relação ao analfabetismo do grupo? Se sim, de que maneira? Se não, como você percebe essa questão?

Resposta: Não tenho condições para muitas coisas e elas não se interessam. Isso é uma pena porque as coisas demoram mais para se resolverem, elas têm uma compreensão muito curta no geral. Sem saber ler e escrever é difícil de serem autônomas.

Questão sete: Qual é a visão de sua participação na AAMA pela sociedade local, o bairro, e como a sociedade em geral e como a sociedade em geral percebe a AAMA no seu ponto de vista? Como você a percebe e como você se percebe nela?

Resposta: [...] Fulano trabalha lá no galpão!”ou “vai trabalhar no galpão”“. As pessoas sabem que eu não faço parte daquela comunidade... Tu não sabes a pobreza que é aquilo, alguns não têm nem comida. As pessoas não me tratam de igual, é como se eu fosse mais que elas, elas esperam respostas de mim, esperam que eu resolva as coisas. [...]

(Fonte: Entrevista com o coordenador da AAMA)

Com relação ao entrevistado coordenador, percebemos que ele procura desenvolver relações autônomas com o grupo, ao responder questionamentos de maneira a valorizar a participação das mulheres associadas, no entanto, enfrenta resistências pela maneira de seu dizer. O coordenador desse grupo de catadoras mostra através do seu dizer certo descontentamento, talvez até frustração, pela passividade das trabalhadoras, que esperam ordens, mando, pois “elas esperam um chefe, alguém de 'fora' que diga o que fazer e como fazer”; também ‘não querem’ pensar.

Mediante esses depoimentos, percebemos no discurso do coordenador cenografias construídas que nos remetem a um ethos de submissão que caracterizaria as associadas, que, em contrapartida, atribuem a esse representante comunitário, e esperariam dele, atitudes mais enérgicas no comando do grupo - um ethos gerencial coercitivo. Quando esse coordenador enuncia que 'elas não querem pensar', podemos inferir desse discurso que as mulheres 'catadoras' prefeririam obter prescrições ao invés do saber investido, da experiência, que lhes proporcionariam maior empoderamento das ações nesse contexto laboral, ou seja, as associadas não fazem o 'uso de si, visto que "as normas não antecipam tudo. Então, trabalhar é arriscar [...] (SCHWARTZ, 2010b, p. 191).

Diante desse cenário, instaura-se o que Schwartz (2010) denomina 'dramática do uso de si' que são vivenciadas diariamente, tanto pelo coordenador quanto pelas trabalhadoras. Ressaltamos que o trabalho implica escolhas e que, muitas vezes, estas são difíceis para o trabalhador, e isso gera desconforto em vista de que as opções não garantem o sucesso final da atividade. Ainda, segundo esse autor, a partir das dramáticas, verificamos o visível e o invisível do trabalho. O visível, a realização da atividade, é facilmente apontada, porém o invisível do trabalho está no debate das normas, nas trocas linguageiras. Ampliando essa reflexão, Freitas (2010, p. 191) enfatiza que "trabalhar é sempre um drama no sentido de que envolve o trabalhador por inteiro; é o espaço de tensões problemáticas, de negociações de normas e valores”. 
Schwartz (2010a, p. 37) menciona que "a ergologia constitui-se em um projeto de melhor conhecer e, sobretudo, de melhor intervir sobre as situações de trabalho para transformá-las”. Dessa forma, essa disciplina (a ergologia) valoriza o trabalhador ao convocá-lo a conhecer e, se necessário, renormalizar as prescrições ao fazer uso de si, em vista de melhores resultados no processo de desenvolvimento da atividade. A ergologia convoca o trabalhador como sujeito possuidor de saberes a desenvolver a atividade e intervir sobre as prescrições, observando a possibilidade de trabalhar de maneira diferente da estabelecida pela hierarquia. Em vista disso, Freitas (2010, p. 191, grifo do autor) ressalta que "a expressão uso de si remete ao fato de que não há somente execução nessa dramática, mas um uso. É a pessoa sendo convocada em toda a sua subjetividade, com toda a mobilização que qualquer abordagem taylorista jamais pode alcançar”.

Verificamos que o objetivo principal de coordenador é que as associadas se apropriem da entidade, a partir de seus saberes constituídos e investidos e, dessa forma, passem a gerir o empreendimento. Todavia, verificamos que as trabalhadoras atribuem unicamente ao coordenador a gerência da Associação (respostas às questões 3, 5 e 6), consideram-no a pessoa que possui saberes, estudos, conhecimentos e, portanto, o detentor do poder.

Consoante Schwartz (2011b, p. 34), existem normas antecedentes que "estão próximas do trabalho como prescrições, procedimentos, constrangimentos, relações de autoridade, de poder, mas também os saberes científicos, técnicos, regras jurídicas, as regras capitalizadas”, enfim tudo o que precede a realização de uma atividade. Por conseguinte, o trabalho prescrito é aquele que vem da hierarquia, ou o que está dito e deve ser realizado (SCHWARTZ, 2011a). Já o trabalho real, segundo o mesmo autor, implica a execução do ato laboral, se a atividade é desenvolvida exatamente do modo que foi prescrita ou se passa por renormalizações compreendidas como "gestões de variabilidades".

De acordo com Souza-e-Silva (2004), a atividade de trabalho é uma resposta às prescrições determinadas no seu exterior e, dessa forma, pode ser reformulada conforme as necessidades que se apresentam. Compreendemos, dessa maneira, que as prescrições são importantes para definir o trabalho e como ele deve ser realizado pelo trabalhador para que esse se sinta seguro ao vislumbrar a realização da atividade. É o caso que constatamos nesse embate discursivo manifestado pelo coordenador entrevistado: ele almejaria maior engajamento das associadas na gestão do trabalho, no uso de si, no entanto, elas ficam à espera do 'uso de si pelo outro', no caso o coordenador. E aí configura-se, novamente, o estabelecimento de uma "dramática do uso de si', pois “em uma organização do trabalho, há uma realidade coletiva e, ao mesmo tempo, ninguém é substituível por ninguém. Dito de outro modo, "as pessoas não são anônimas; são pessoas singulares com sua história" (DURRAFOURG; DURRIVE, 2010, p. 192), isso porque o trabalho é uma realidade profundamente coletiva e ao mesmo tempo individual, por conta da sua singularidade, então, conforme Durrafourg e Durrive (2010, p. 192), “meu trabalho como 'uso' é atravessado pelos outros. Reciprocamente, a maneira pela qual eu trabalho diz qualquer coisa da sociedade na qual eu quero viver”.

Salientamos que o coordenador, ao trabalhar diretamente com o grupo, faz uso de si por si, bem como de si pelos outros, representando o Projeto Transformação para as trabalhadoras e a sociedade, dedicando tempo para atuar junto à Associação. Schwartz (2002) afirma que quando se diz que o trabalho é uso de si, isto quer então dizer que ele é o lugar de um problema, de uma tensão problemática, de um espaço de possíveis sempre a negociar. Dessa forma, o coordenador se posiciona de um lugar que não é o mesmo das associadas: ele faz faculdade, elas, quase todas, analfabetas. Na resposta à questão número 
3, o coordenador enuncia elas, porém, ao representar a Associação, ele dá voz à entidade (FREITAS, 2008) e a representa formalmente, é possuidor de saberes constituídos que projetam uma imagem de si - um ethos de poder, hierárquico.

Ainda, podemos considerar que, segundo Borges e Zambroni-de-Souza (2010), os saberes são constituídos, os saberes formais e os saberes investidos - isto é, a historicidade do sujeito -, e ambos mostram-se estreitamente vinculados à realização do trabalho. Conforme Nouroudine (2002, p. 19), “as atividades, os saberes e os valores são propriedades intrínsecas ao trabalho, que se manifestam no cruzamento e na contaminação mútua”.

Nesses excertos discursivos extraídos da entrevista com o coordenador da AAMA, o "eu" evidencia uma cenografia associada à imagem de pessoas que detêm responsabilidades e capacidades com referência à vida no trabalho, bem como à vida pessoal. As expressões também enfatizam os diversos valores e estatutos das posições ocupadas pelos personagens de ação da AAMA como participantes de uma estrutura de trabalho. O uso de "eu" nos enunciados também revela a subjetividade dos sujeitos ao se apropriarem de suas funções na Associação.

O coordenador entrevistado, ao enunciar-se fazendo uso do $e u$, refere-se à ação que realiza, ou tenta realizar, com o grupo. Nessa maneira de dizer, o percebemos discursivamente como um sujeito instigador e que desacomoda o grupo ao chamá-lo a reagir e criar soluções diante das adversidades do cotidiano da Associação. Ao instigar as trabalhadoras, busca que elas façam a gestão ou o 'uso de si'. "A construção de uma imagem de si no discurso tem a capacidade de modificar as representações prévias, de contribuir para a instalação de imagens novas e de transformar equilíbrios, contribuindo para a dinâmica de campo" (AMOSSY, 2008, p. 138). A cena de enunciação construída pelo discurso não é puramente imaginária, pois a autoridade do locutor, do enunciador, no caso o coordenador da AAMA, não advém somente e das modalidades linguageiras da troca simbólica da qual ele participa. Essa autoridade "é também produzida pelo discurso em uma troca verbal que visa a produzir e a fazer reconhecer sua legitimidade" (AMOSSY, 2008, p. 138), e daí se constrói um ethos de empoderamento.

Nesse sentido, a relação entre coordenador e associadas não é exatamente uma relação de empregador/funcionário, mas ele, como personagem que faz parte de um cenário sócio-histórico, representa a "figura paterna" (ethos paternal), aquele que, com sua subjetividade, conduz e guia a entidade no seu todo, o que justifica a necessidade das associadas de que ele se imponha mais frente ao grupo, constituindo uma cenografia de família, na qual o 'pai' toma conta, cuida e a direciona, evidenciando, desse modo, um ethos cuidador para com as associadas, que assim desejam. Essa situação aponta, segundo Maingueneau (2008b, p. 71), que o "ethos se mostra, não é dito".

É importante, igualmente, apresentar enunciados da entrevista feita com a associada da AAMA, para que possamos compreender a cenografia e o ethos construídos nesses dizeres. Vejamos: 


\section{Quadro 2 - Segmento discursivo 2}

Questão 1: Por que você trabalha como catador de material reciclável e não em outra atividade?

Resposta: [...] Quando eu comecei não sabia nada, aí a gente teve formação com o Sr. Paulo da empresa X. Ele ensinou tudo, como separar, o que é bom e o que é ruim, que não tem venda. Agora quem é mais antiga e sabe ensina pras novas, aí a gente trabalha de duas a duas, que é pra quem sabe ensinar quem não sabe. Agora eu que ensino.

Questão 2: Como e por quem são distribuídas as tarefas na AAMA?

Resposta: [...] Quando tem reunião todo mundo para, daí a gente só recebe de quem vem entregar. A gente já sabe o que tem que fazer, nem precisa dizer, só quando tem gente nova, que é bem seguido, e daí o coordenador vem pra explicar o regulamento e depois a gente tem que ensinar trabalhar, separar.[...]

Questão 6: Qual a função do voluntário na Associação?

Resposta: O coordenador é o nosso voluntário. Ele representa várias entidades da Igreja Projeto Transformar. Ele é bom, mas já tivemos monitores de pulso mais firme, que diziam se a gente estava certa ou errada, eles diziam "Oh, se vocês forem por aqui, podem ir, mas vai dar tudo errado, vocês é que sabem”. Daí a gente sabia que tinha de ir pela ideia dele pra não se dar mal. O coordenador joga tudo pra nós decidir. Ele tinha que insistir um pouco, fazer com que o pessoal acatasse as ordens. Eu já falei pra ele.

(Fonte: Entrevista com uma associada da AMAA)

Diante dos depoimentos dessa entrevistada, destacamos que os enunciados nem sempre são compreendidos pelos coenunciadores, pois as palavras, organizadas em enunciados construídos a partir dos saberes constituídos e investidos do enunciador, são portadoras de significados, muitas vezes, diversos do léxico. Constatamos, assim, nos depoimentos dessa entrevistada, uma cenografia de queixa com marcas de singularidade que indicam a particularidade do seu discurso, "Eu já falei pra ele”, revelando crenças quanto a um ethos de dependência em relação ao coordenador, bem como um forte enraizamento cultural nos moldes do taylorismo, quando não era necessário e nem permitido que o trabalhador decidisse ou contribuísse de forma participativa. A escolha da cenografia não é indiferente. Isso porque o discurso desenvolve-se a partir de uma cenografia específica, pretende ser eficaz instituindo a própria cena de enunciação que o legitima.

Nesses segmentos discursivos, nas questões apresentadas, percebemos que há 'déficit de prescrições', que “é a não explicitação ao trabalhador das regras para desenvolver a atividade [...]” (SOUZA-E-SILVA, 2008, p. 11). Se as prescrições não estão bem claras e não permitem que a trabalhadora se sinta segura ao realizar essa atividade, ela não tem seus saberes constituídos solidificados e há uma lacuna a ser preenchida pelo grupo, que, por sua vez, ainda não percebeu esse fato. Diante disso, notamos que há prescrições descendentes, as que vêm da hierarquia, e prescrições ascendentes, aquelas desenvolvidas no ambiente de trabalho. Como não está acorrentado às normas, o sujeito age sobre o trabalho e, a partir de seus saberes constituídos e investidos, renormaliza as prescrições. Contudo, a ausência de prescrições promove inseguranças ao trabalhador.

Quando a entrevistada afirmou 'Agora sou eu que ensino', percebemos a subjetividade, a mobilização da iniciativa e da responsabilidade da trabalhadora. Nesse caso, o 'eu' aparece como a pessoa que sabe e determina situações, sendo-lhe, portanto, reservado um lugar de saber e de certo poder dentro da associação. Ressaltamos que o 'eu' é o que prescreve, porém as prescrições por ele determinadas implicam um debate de normas, ou 'debate de valores'. Verificamos nas palavras da entrevistada, mulher catadora, 
que ao utilizar “Agora sou eu que ensino”, “Agora quem é mais antiga e sabe ensina pras novas” (agora ela sabe, antes não sabia) ocupa um lugar discursivo, o do tempo (AGORA) e de um lugar (AQUI) nesse momento particular do dizer; essas marcas enunciativas têm relação estreita com a dêixis discursiva, cujo enunciador (a entrevistada) se manifesta através de um tom que "permite ao leitor construir uma representação do corpo do enunciador (e não, evidentemente, do corpo do autor efetivo). A leitura faz, então, emergir uma instância subjetiva que desempenha o papel de fiador do que é dito" (MAINGUENEAU, 2011, p. 98). Falamos, então, de incorporação para designar a ação do ethos sobre o coenunciador, que leva o coenunciador a conferir um ethos ao seu fiador, enunciação essa que lhe dá corpo.

Podemos verificar nessa materialidade enunciativa, presente nos depoimentos da entrevistada, que essa trabalhadora 'catadora' faz a gestão de si (o uso de si) ao informar que "Agora eu ensino", portanto, renormaliza sua atividade a partir do prescrito; desse modo, também, utiliza-se do saber investido e faz uso de si pelo outro, em relação às trabalhadoras mais novas, pois “Agora quem é mais antiga ensina pras novas”. Verificamos uma cenografia que se constrói mediante a renormalização do prescrito (saber constituído), pois instaura saberes da experiência, do vivido na prática da atividade; dessa situação de enunciação articula-se uma imagem de si da entrevistada: um ethos mostrado de liderança, de poder e de saber, por isso ocupa no espaço discursivo - da Associação uma posição de 'respeito e de aceitação pelas demais integrantes do grupo'.

Diante de tais manifestações linguageiras, podemos destacar que "A ergologia sustenta que toda a atividade de trabalho é sempre singular, porém em níveis muito diferenciados. Às vezes, a variabilidade é mínima, difícil de ser percebida externamente, contudo jamais completamente inexistente.(TRINQUET, 2010, p. 99). E nesse sentido, é importante destacar que "a importância do saber investido reside no fato de colocar questões práticas, derivadas da atividade profissional”. E isso é “o que obriga os detentores dos saberes constituídos (eruditos) de se aproximarem, uns dos outros, para encontrarem respostas pertinentes e saírem de seus saberes genéricos, para se implicarem na realidade da situação analisada. (TRINQUET, 2010, p. 99, grifo do autor).

Segundo Borges e Zambroni-de-Souza (2010, p. 152), para a ergologia, “colocamos em marcha um saber pessoal, que é o resultado de nossa história individual, sempre singular, temos dito, adquirida em nossa própria experiência profissional e em outras e que reenvia a nossos valores, nossa educação, ou seja, à nossa personalidade”. Nos enunciados da entrevistada, é possível depreender que a entrevistada não reconhece os saberes investidos, da experiência, que possui e que desenvolveu durante a sua vida. Ela atribui o saber a uma pessoa de 'fora' da Associação e às associadas mais antigas. No entanto, no instante em que enuncia "agora eu ensino", percebemos que se apropriou dos saberes investidos, tornando-os constituídos, porque está numa posição hierárquica mais elevada: ela sabe, as novas não.

As práticas linguageiras são constatadas a partir da vocalidade, nos gestos e nas expressões. Conforme Nouroudine (2002, p. 21, grifo do autor), "a linguagem é econômica, dado que a comunicação, em situação de trabalho e durante a atividade”, pressupõe a gestão do tempo que o compreende. Essa situação é muito clara em alguns momentos de trabalho intensivo das associadas, que não se permitem às práticas linguageiras "livres", tendo em vista desenvolverem uma atividade com tempo determinado para sua execução. Portanto, linguagem e trabalho estão intimamente ligados.

A partir de nossa análise, ao percebermos os princípios ergológicos, são constituídas cenografias que resultam no ethos discursivo. Em consonância com Maingueneau (2011, p. 88), “a cenografia só se manifesta plenamente se puder controlar o 
próprio desenvolvimento, manter uma distância em relação ao coenunciador”. Dessa forma, a cenografia empresarial se constitui pela associação de catadores de materiais recicláveis, por meio dos enunciados de suas trabalhadoras e do coordenador nas relações linguageiras de trabalho. Num primeiro momento, percebemos o ethos de uma entidade assistencialista, porém o que se constata é que seus propósitos almejam autonomia intelectual e financeira.

Nesse sentido, voltando-nos para os elementos da cenografia, observamos uma Associação jovem, organizada e embasada nos preceitos da economia popular. A AAMA é respeitada, e seu objetivo é oferecer estabilidade financeira às associadas, desenvolvendo suas competências gestoras. Ela exemplifica e comunica aos moradores desse lugar, bem como à sociedade em geral, a importância da coleta seletiva, e a comunidade, ao realizar a coleta seletiva em suas residências, corresponde ao comunicado explícito emitido pela entidade. A isso podemos relacionar o que afirma Souza-e-Silva (2004, p. 85): “a atividade é uma resposta às prescrições determinadas exteriormente ao trabalhador e, simultaneamente, ela é suscetível de transformá-las”.

A AAMA apresenta-se por cenografias variadas - reuniões, comércio (compra/venda), construção de saberes (estudos de formação) - e, também, por uma cenografia política, em que, em vista a persuadir o coenunciador, o discurso do enunciador deve "captar o seu imaginário e atribuir-lhe uma identidade, por meio de uma cena de fala valorizada” (MAINGUENEAU, 2011, p. 92).

Apontando elementos da cenografia, identificamos o coordenador como um jovem estudante bem-sucedido e relativamente satisfeito em trabalhar com esse grupo de pessoas, embora, por meio do seu dizer, "elas gostariam que eu mandasse, elas esperam um chefe, alguém de fora que diga o que fazer e como fazer....não querem pensar [...], verificamos, respectivamente, o uso de si pelas catadoras que querem ser geridas e o uso de si por si com seus saberes implícitos, pois, se é colaborador, voluntário, é porque tem o poder de mando, requer obediência, e também sabe como fazer o trabalho. Dessa maneira, apuramos que, em situações de trabalho, as práticas linguageiras são fundamentais, em vista de que, a partir delas, depreendemos as cenografias e os ethos instituídos de diversas formas em instituições e trabalhadores.

O coordenador coloca-se numa posição de parceria com os trabalhadores, entretanto ocupa o lugar daquele que "sabe", cenografia professoral, mesmo ao instigar os associados a buscarem soluções para os problemas da entidade. O enunciador apresenta-se, ainda, como fiador, pois se considera responsável pelo grupo e, muitas vezes, responde por ele. Maingueneau (2008b, p. 72) destaca que "o fiador [...] vê-se, assim, investido de um caráter e uma corporalidade”. Em razão disso, o enunciador, representante da Igreja Católica, pressupõe um caráter confiável, e esse caráter "corresponde a um feixe de traços psicológicos"; a corporalidade "está associada a uma compleição corporal, mas também a uma forma de vestir-se e de mover-se no espaço social” (MAINGUENEAU, 2008b, p. 72).

Destacamos, também, que o trabalho realizado pelas trabalhadoras é pesado, árduo e envolve diretamente o manuseio e o contato com o lixo produzido e descartado pela sociedade de consumo; entretanto, elas consideram que, por fazerem parte da AAMA, suas vidas estão mais confortáveis e organizadas. É notória, ainda, a cenografia de luta, da conquista de um espaço construído e reconhecido pela sociedade em geral e sobre o qual algumas dessas associadas se orgulham, "é o único lugar em que eu trabalhei até hoje”, deixando transparecer o resgate da autoestima, bem como a conquista do pertencimento a um setor produtivo que está em evidência.

Inferimos, portanto, que as trabalhadoras não se sentem capazes de solucionar os seus problemas de maneira autônoma, sem a ajuda do coordenador; parecem não fazer uso 
de si para as resoluções de ordem administrativa. O contrário, contudo, acontece na realização e na renormalização de tarefas braçais. Nesse sentido, o ethos discursivo, decorrente dos enunciados da associada entrevistada, caracteriza a imagem de fragilidade, tanto por parte da trabalhadora quanto em relação à própria Associação. Conforme Maingueneau (2008c, p. 17, grifo do autor), "o ethos é uma noção discursiva, ele se constrói através do discurso, não é uma 'imagem’ do locutor exterior a sua fala”.

No sentido de encaminhar a finalização dessa reflexão, acreditamos ser oportuno, ainda, ressaltar que o coordenador entrevistado conduz e determina as intenções da Associação, entretanto as associadas determinam, coletivamente, a realização das atividades braçais. As trabalhadoras veem o trabalho como prescrições e as aguardam, as solicitam no intuito de desenvolver as atividades a contento. Contudo, recebem as prescrições como “orientação" por parte do coordenador, e não como um imperativo, o que as desagrada e desconforta, pois, ao mesmo tempo em que querem ser autônomas, não conseguem se apropriar da Associação, do coletivo do trabalho, não se sentem aptas a coordenar essa entidade. A esse respeito, o representante do Projeto Transformação busca e tenciona que a AAMA se liberte dos moldes tayloristas de administração, convoca as trabalhadoras para assumirem o emprendimento com base em uma "construção de valores" desenvolvidos diariamente no trabalho. A imagem de si aqui depreendida é que a AAMA é uma entidade democrática que permite e convoca as associadas a apropriarem-se dos saberes constituídos e investidos, que façam a gestão de si, a partir do movimento favorável de incentivo que faz o coordenador do Projeto, que em última instância é a voz que alimenta e retroalimenta o processo de interação verbal - que procura dar sustentabilidade ao 'negócio', mas, acima de tudo, que luta pela inserção social das mulheres 'catadoras', que elas se desenvolvam como gestoras de si, façam esse uso de si por si e pelo outro, de forma que esse processo lhes confiram legitimidade e reconhecimento social pelo importante papel que fazem: ajudam a construir uma cidade mais limpa, mais sustentável, mais humana e menos estigmatizada/estereotipada.

\section{Considerações finais}

Este estudo, de cunho interdisciplinar, entre a linguística do discurso e a ergologia teve como principais autores Schwartz (2006, 2010a, 2010b, 2011b) e Trinquet (2010), e em relação à linguagem sobre o trabalho, Nouroudine (2002). No que diz respeito aos pressupostos da semântica global, utilizamos Maingueneau (1984/2008a, 2008b, 2011) e alguns de seus estudiosos.

O tema do estudo, que compreendeu as práticas discursivas em comunidades em situação de vulnerabilidade social, teve como delimitação a análise dos discursos de integrantes de uma associação de material reciclável, a Associação Amigos do Meio Ambiente, pertencente ao bairro Popular na cidade de Passo Fundo, RS.

O problema de pesquisa foi assim formulado: como se constroem discursivamente a cenografia e o ethos manifestados através de práticas de linguagem em uma associação de material reciclável e de seus catadores? Com base no conteúdo das entrevistas realizadas coordenador e uma mulher catadora -, foi demonstrado que essa entidade compreende diversas cenografias e, consequentemente, variados ethé discursivos. Vislumbramos que na AAMA existe hierarquia constituída, em cujo topo está o coordenador, com seus saberes constituídos e investidos. Constatamos, nesse sentido, que as prescrições vêm da hierarquia, porém a(s) trabalhadora(s) não é(são) totalmente passiva(s), na medida em que faz(em) intervenções junto ao 'superior', participa(m) das decisões e, a passos lentos, 
apropria(m)-se de novos saberes, confrontando-se com dramáticas de uso de si ao realizar(em) as atividades no trabalho.

Ao abordar a ergologia e a semântica global, depreendemos, por meio de marcas discursivas, como se constroem a cenografia e o ethos discursivo da Associação, objetivo desta pesquisa, o que possibilitou, também, a compreensão da relação de trabalho havida entre as mulheres ‘catadoras' e o coordenador que acompanha o Projeto Transformação. Dessa forma, investigando as práticas discursivas orais, posteriormente transcritas para fins de registro e análise, manifestadas pela integrante da Associação e pelo agente social que a conduz, percebemos diversos modos de pensar o trabalho, a própria atividade, e as dramáticas do uso de si que envolvem o coordenador e as associadas. Esses registros, realizados em vista da observação - quem fala, de que lugar fala(m) e para quem fala(m) -, permitiram comparar possíveis aproximações e distanciamentos entre os interlocutores da Associação - ora prevalecem situações de diálogo, ora de confrontos, é o embate entre o prescrito e o real, as normas e renormalizações, enfim um debate de valores', que envolve elementos culturais de quem coordena e daquelas que são subordinadas.

Vislumbramos a possibilidade de contribuir, de forma prática, com essa Associação, partindo do que foi apreendido por meio deste estudo. Torna-se viável, por exemplo, participar das reuniões de formação e colaborar em relação às necessidades da AAMA, que estiverem ao alcance dos autores dessa pesquisa, no que se refere à atividade e à linguagem no e sobre o trabalho.

Em relação ao meio acadêmico, este estudo proporcionou uma aproximação entre o cultural e o senso comum, tendo a pretensão de promover novas interlocuções, por meio do poder público, da universidade, das entidades assistenciais, e por que não dizer, da própria sociedade organizada. Esperamos, mesmo que isso pareça utópico, que não se percam os vínculos já constituídos.

\section{REFERÊNCIAS}

AMOSSY, R. O ethos na interseção das disciplinas: retórica, pragmática, sociologia dos campos. In: Contexto, 2008. p.119-144. (Org.) Imagens de si no discurso: a construção do ethos. São Paulo:

BORGES, M. E. S.; ZAMBRONI-DE-SOUZA, P. C.. Entrevista: Pierre Trinquet e o ponto de vista da atividade em formação profissional e segurança no trabalho. Cadernos de Psicologia Social do Trabalho, São Paulo, vol. 13, n. 1, p. 149-157, 2010. Disponível em: http://www.revistasusp.sibi.usp.br/pdf/cpst/v13n1/v13n1a12.pdf. Acesso em: 26 set. 2012.

CANGUILHEM, G. O normal e o patológico, Rio de Janeiro, Forense Universitária, 1990.

CLOT, Y. A função psicológica do trabalho. Tradução de Adail Sobral. 2. ed. Petrópolis, RJ: Vozes, 2007.

CLOT, Y. Clínica do trabalho e clínica da atividade. In: BENDASSOLLI, P. F.; SOBOLL, L. A. (Orgs.). Clínicas do trabalho: novas perspectivas para compreensão do trabalho na atualidade. Tradução de Maria Helena C. V. Trylinsk. São Paulo: Atlas, 2011. p. 71-83.

DI FANTI, M. G. C. Linguagem e trabalho: diálogo entre a translinguística e a ergologia. Desenredo, Revista do Programa de Pós-Graduação em Letras da Universidade de Passo Fundo, v. 8, n. 1, p. 309-329, jan./jun. 2012.

DURAFFOURG, J.; DURRIVE, L. O trabalho e o ponto de vista da atividade. In: SCHWARTZ, Y.; DURRIVE, L. (Orgs.). Trabalho e ergologia: conversas sobre a 
atividade humana. Coord. da tradução e revisão técnica: Jussara Brito e Milton Athayde. 2. ed. Niterói: EdUFF, 2010. p. 47-82.

FAÏTA, D.. Análise das práticas linguageiras e situação de trabalho: uma renovação metodológica imposta pelo objeto. In: SOUZA-E-SILVA, M. C. P.; FAÏTA, D. (Orgs.). Linguagem e trabalho: construção de objetos de análise no Brasil e na França. Tradução Inês Polegatto, Décio Rocha. São Paulo: Cortez, 2002, p. 45-60.

FREITAS, E. C. Cultura, linguagem e trabalho: comunicação e discurso nas organizações. Desenredo, Revista do Programa de Pós-Graduação em Letras da Universidade de Passo Fundo, v. 7, n. 1, p. 104-126, jan./jun. 2011.

FREITAS, E. C. Linguagem na atividade de trabalho: éthos discursivo em editoriais de jornal interno de empresa. Desenredo, Revista do Programa de Pós-Graduação em Letras da Universidade de Passo Fundo, v. 6, n. 2, p. 170-197, jul./dez. 2010.

FREITAS, E. C.. A semiolinguística no discurso: práticas de linguagem em situações de trabalho. Desenredo, Revista do Programa de Pós-Graduação em Letras da Universidade de Passo Fundo, v. 4, n. 2, p. 262-283, jul./dez. 2008.

ICAZA, A. M. S.; TIRIBA, L. Economia popular. In: CATTANI, A. D. (Orgs.). A outra economia. Porto Alegre: Veraz Editores, 2003. p. 15-20.

MAINGUENEAU, D. (1984). Uma semântica global. In: . Gênese dos discursos. Tradução Sírio Possenti. São Paulo: Parábola Editorial, 2008a. p. 75-97.

MAINGUENEAU, D. A propósito do ethos. In. MOTTA, A. R.; SALGADO, L. (Orgs.). Ethos discursivo. São Paulo: Contexto, 2008c. p. 11-29.

MAINGUENEAU, D. Doze conceitos em análise do discurso. Tradução Adail Sobral et al. São Paulo: Parábola Editorial, 2010.

MAINGUENEAU, D. Ethos, cenografia, incorporação. In: AMOSSY, R. (Org.). Imagens de si no discurso: a construção do ethos. São Paulo: Contexto, 2008b. p. 69-92.

MAINGUENEAU, D. Novas tendências em análise do discurso. Tradução de Freda Indursky. 3. ed. Campinas, SP: Pontes; Editora da UNICAMP, 1997.

MAINGUENEAU, D.. Análise de textos de comunicação. 6. ed. Tradução de Cecília P. de Souza-e-Silva, Décio Rocha. 2. ed. São Paulo: Cortez, 2011.

NOUROUDINE, A. A linguagem: dispositivo revelador da complexidade do trabalho. In: SOUZA-E-SILVA, M. C.P. ; FAÏTA, D. (Orgs.). Linguagem e trabalho: construção de objetos de análise no Brasil e na França. Tradução Inês Polegatto, Décio Rocha.

PRODANOV, C. C.; FREITAS, E. C. Metodologia do trabalho científico: métodos e técnicas da pesquisa e do trabalho acadêmico. Novo Hamburgo, RS: Feevale, 2009.

RIBEIRO, R.V. Teorias da administração. Curitiba: IESDE Brasil S.A., 2007.

São Paulo: Cortez, 2002. p. 17- 30.

SCHWARTZ, Y. Conceituando trabalho, o visível e o invisível. Trabalho, Educação e Saúde, Rio de Janeiro: Fundação Oswaldo Cruz, v. 9, supl. 1, p. 19-45, 2011 b.

SCHWARTZ, Y. Disciplina epistêmica, disciplina ergológica: paideia e politeia. In: Proposições - Revista quadrimestral da Faculdade de Educação - UNICAMP, v. 13, n. 1 (37), p. 126-149, jan./abr. 2002. 
SCHWARTZ, Y. Entrevista. Trabalho, Educação e Saúde, Rio de Janeiro: Fundação Oswaldo Cruz, v. 4, n. 2, p. 457-466, 2006.

SCHWARTZ, Y. Manifesto por um ergoengajamento. In: BENDASSOLLI, P. F.; SOBOLL, L. A. P. (Orgs.). Clínicas do trabalho: novas perspectivas para compreensão do trabalho na atualidade. Tradução de Denise Alvarez e Maristela França. São Paulo: Atlas, 2011a. p. 132- 166.

SCHWARTZ, Y. Trabalho e ergologia. In: SCHWARTZ, Y.; DURRIVE, L. (Orgs.). Trabalho e ergologia: conversas sobre a atividade humana. Coord. da tradução e revisão técnica: Jussara Brito e Milton Athayde. 2. ed. Niterói: EdUFF, 2010a. p. 25-46.

SCHWARTZ, Y. Trabalho e uso de si. In: (Orgs.). Trabalho e ergologia: conversas sobre a atividade humana. Coord. da tradução e revisão técnica: Jussara Brito e Milton Athayde. 2. ed. Niterói: EdUFF, 2010b, p. 187-204.

SCHWARTZ, Y. Trabalho, emprego e cidadania. In: (Orgs.). Trabalho $e$ ergologia: conversas sobre a atividade humana. Coord. da tradução e revisão técnica: Jussara Brito e Milton Athayde. 2. ed. Niterói: EdUFF, 2010c. p. 274-292.

SILVA, E. G. Os (des)encontros da fé. Análise interdiscursiva de dois movimentos da Igreja Católica. 293 f. 2006. Tese (Doutorado) - Departamento de Linguística do Instituto de Estudos da Linguagem da Universidade Estadual de Campinas, Campinas, SP, 2006.

SOUZA-E-SILVA, Maria C. A dimensão linguageira em situações de trabalho. In: SOUZA-E-SILVA, Maria Cecília P.; FAÏTA, Daniel (Orgs.) Linguagem e trabalho: construção de objetos de análise no Brasil e na França. Tradução Inês Polegatto, Décio Rocha. São Paulo: Cortez, 2002. p. 61-76.

SOUZA-E-SILVA, Maria C. Atividade de linguagem, atividade de trabalho: Encontro de Múltiplos Saberes. Revista Intercâmbio, São Paulo: LAEL/PUC-SP, v. 18, p. 1-21, 2008. Disponível em: http://www.revistas.pucsp.br/index.php/intercambio/article/view/3549>. Acesso em: 18 jan. 2012.

SOUZA-E-SILVA, Maria C. O ensino como trabalho. In: MACHADO, A. R. (Org.). O ensino como trabalho: uma abordagem discursiva. São Paulo: Eduel, 2004. p. 81-104.

SOUZA-E-SILVA, Maria C.; ROCHA, D. Resenha de "Gênese dos discursos" de Dominique Maingueneau. ReVEL, v. 7, n. 13, p. 1-25, 2009. Disponível em: <http://www.revel.inf.br>. Acesso em: 11 nov. 2012.

TRINQUET, P. Trabalho e educação: o método ergológico. Revista HISTEDBR On line, Campinas, número especial, p. 93-113, ago. 2010. Disponível em: $<$ http://www.histedbr.fae.unicamp.br/revista/edicoes/38e/art07-38e.pdf>. Acesso em: 15 jul. 2012.

WISNER, A. A inteligência no trabalho: textos selecionados de ergonomia. São Paulo: Fundacentro, 1994.

Recebido em fevereiro de 2013.

Aprovado em abril de 2013. 